Vol. 1, No. 1, 2020

\author{
Oleksii Lobashov ${ }^{1}$, Mykola Boikiv ${ }^{2}$ \\ 1. O.M. Beketov National University of Urban Economy in Kharkiv \\ Marshal Bazhanov Str. 17, Kharkiv, Ukraine, 61002
}

2. Lviv Polytechnic National University

Bandery Str. 12, Lviv, Ukraine, 79000

(C) Lobashov O., Boikiv M., 2020

https://doi.org/10.23939/tt2020.01.054

\title{
INCREASING THE COMPLEX INTERSECTIONS FUNCTIONING EFFICIENCY BY RESTRICTION OF LEFT-TURN TRAFFIC FLOWS
}

\begin{abstract}
Summary. Providing rapid and safe traffic in cities requires the use of a set of planning and organizational measures. While the implementation of architectural-planning measures requires, except for significant investments, a quite long period, organizational measures can lead to a temporary but relatively rapid effect. For this purpose, an analysis of traffic flow metrics on the approaches to the intersection, traffic light cycle, and the traffic phasing is carried out. Conducted research indicates that left-turn flows cause significant delays and reduce traffic safety at the intersection. Therefore, increasing the efficiency of the crossroads needs redevelopment measures by restriction of the left-turn flows on the main road, change of the traffic flows phasing and optimizing the traffic light cycle. In the presence of adjacent intersections, the scheme of left turn realization is developed. The simulation of intersection functioning in existing conditions and under the change of left-turn flows movement organization is carried out in the PTV Vissim software environment. It is established that restriction of the left-turn flows at the controlled intersection allows to optimize the traffic light cycle and equip it so that the average delay for traffic flows will decrease in comparison with the current state.
\end{abstract}

Key words: controlled intersection, traffic light control, traffic phasing, maximal vehicle queue length, average queue length, time in traffic jams, traffic flow, traffic lane, left-turn traffic flow.

\section{INTRODUCTION}

With the increase of traffic flow intensity on urban streets and roads, the problem of providing the safety of road users' interaction exacerbates significantly. Death rates on the roads in Ukraine far exceed the average indicator in the countries of the European Union.

The development of effective measures, aimed at reducing accidents and their implementation by the services of traffic supervision requires a clear definition of factors that affect the emergence of hazardous areas - places of traffic accident concentration [1]. While finding the solution to modern problems of improving traffic management together with improving the traffic efficiency (provision the required speed of movement, reduction the traffic delays at intersections, etc.) much attention is paid to the issue of improving the safety of vehicles.

The rapid growth of the motorization level has led to a significant increase in traffic intensity, and as a result, the load on the country's road infrastructure. Studies of traffic flows show that the highway road network operates at the limit of its capacity and some areas of the network are completely depleted.

Improvement of the traffic flow management technology is an important and actual task that is related to the improvement of the efficiency of urban transport systems. Analysis of Ukrainian and foreign 
studies indicates that in most approaches such parameters as a traffic light regulation mode, the number of regulation phases, choice of the principle of traffic organization are appointed at the engineering level and have no exact justification. This generally limits the ability to control traffic lights, both in terms of efficiency and for traffic safety. Therefore, improving the efficiency of the controlled intersections is a topical task. The change of traffic organization at intersections should provide a sufficient level of traffic safety and all road users service.

\section{RESEARCH STATEMENT}

In modern conditions of cities development, a need in the development of the method for justification and evaluation of traffic organization schemes and principles of traffic management at difficult intersections appears. At controlled intersections with high traffic intensity, traffic phasing scheme and the priority of passing traffic flows plays an important role in ensuring traffic safety. The permanent complication of the road conditions requires the improvement of technologies and technical solutions in traffic management.

To provide a high level of technical and organizational measures on traffic management at controlled intersections, the data characterizing not only traffic flow but also the opportunity to evaluate the efficiency of the intersection are needed.

Among the existing criteria for evaluating the effective management of controlled intersections, the most widely used indicators are the average vehicle delay, the degree of saturation of lanes and the capacity of the intersection. But one of the most important integral criterion, the various project decisions are based on, is considered to be the average delay of vehicles. Therefore, the problem of change and evaluation of traffic organization schemes at controlled intersections is relevant, which will allow the redevelopment of the intersection and achieve its effective operation at minimal financial cost, based on the developed projected solutions.

The aim of the study is the research of the complex intersections functioning effectiveness under the changes of its organization and the evaluation of its operation parameters. This, in the future, in dense urban development, will allow to approach to the choice and justification of the scheme of traffic organization at existing intersections by dispersal of traffic over time and space and by restriction of the left-turn flows.

To achieve the aim of the study, it is necessary to solve such problems:

- to carry out field research of traffic flow indicators at the controlled intersection;

- to carry out experimental measurement of traffic delays on all intersection entrences;

- to create a model for the intersection operation in the software PTV VISSIM environment to evaluate the controlled intersection functioning in existing traffic conditions and taking into account the change in the scheme of movement;

- to determine the trends of change the queue length of cars queue before the stop-line according to the existing and proposed flow chart;

- to develop practical recommendations regarding the change of the traffic management scheme at the intersection.

\section{RESEARCH OF CONTROLLED INTERSECTION AND MODELING OF ITS WORK}

\subsection{A review of research and publications concerning the improvement of controlled intersections efficiency}

Permitted left-turn maneuver at the intersection significantly affects on the number of traffic accidents on it. The analysis of the accidents at controlled intersections in the presence of a left turn shows they are increasing causing serious injuries. This problem can be solved by the implementation of "protected" left turns, i.e. in the presence of separate equipped traffic lanes. This allows vehicles, which turn left, to cross the intersection and, without a conflict with other road users, to perform a maneuver [2]. 
Also, the location of the left turns in a separate control phase requires a higher need in balancing and safety during design and changes in the scheme of traffic organization. So, the authors in their study developed models to determine the most effective type of left-turn traffic light signals, which was based on particular characteristics of the intersection entrence [3].

The main purpose of the effective work increase at controlled intersections is the development of planned stages that reduce delays while maintaining a high level of safety. One of the problems, resulting from this, is a left turn implementation in different conflicts with other traffic flows as such maneuvers can increase the safety of movement when turning, but they can also increase delays and traffic congestion. In the study [4], the experiment, where a simplified unified exponential model to determine the safety on the left-turn lanes based on the comparison of traffic flow intensity and the share of green signal is proposed was conducted. In the arterial streets during peak periods, the significant traffic intensities are observed, and that, in terms of intersection passage optimization, complicates the software solution of relevant problems. This causes the need to carry out studies to determine the delays of the vehicle before intersections, the increase of the intensity of their passages and justify the effective methods of regulation of the intersection passage and coordination of their operation along the entire length of the arterial streets based on their results. [5].

Also, the authors [6] mention in their research that at some large intersections, the frequent change of lanes when turning left can lead to disorganized movement, promoting change of traffic lanes and often leads to accidents. In the study [7], which is devoted to the effect of different types of traffic light control on traffic safety, ten intersections were examined with different types of left turns arrangement. The average intensity of traffic flows per day and the number of accidents on them were taken into account. Analysis of the study indicates that intersections, where left-turn flows are moving with straight flows in one phase, have a higher accident rate than in cases, where a left turn is equipped and has a separate adjustment phase for this. In further studies of the intersection operation effectiveness, it is necessary to avoid left-turn organization in the intersection zone. It will help to improve traffic safety on them.

Controlled intersections are one of the most common types of nodes on the street road network of cities. Traffic congestion and delays appear just at regulated intersections and limit the capacity of streets and roads. Therefore, the quality of traffic management at controlled intersections, first of all, affects the performance of the transport network and the efficiency of transportation processes [8].

The efficiency of functioning of the cities road network is largely determined by the capacity of the controlled intersection. In such nodes, there is an interruption of traffic flow for traffic regulation. Because of this, most controlled intersections have less capacity than approaching roads due to the presence of conflict points of merging traffic [9].

Potential collision with oncoming traffic while turning left belongs to the most dangerous. In the general case, the share of traffic accidents is $25 \%$ from the total of all accidents occurring at such intersections. To reduce the number of accidents a left turn system was designed [10], where the most important, for the efficiency of the system, is to develop the human-machine interface. This is for determining, how the system uses the calculated probability of accidents during the communication with the driver. A study was conducted on a driving simulator with the assessment of a warning strategy for two cases of usage: firstly, the driver stopped before the stop-line to perform a turn, secondly, the driver moves without stopping and turns left. The results showed that when the driver stops before the stop-line to perform the maneuver - it has a positive effect on traffic safety in the area of intersection, but increases the total delay of traffic. Since the saturation flow is generated during dissipation of the vehicle queue at the permission signal and it is defined in the cross-section of the stop-line for one lane, then it is advisable to create the model of the lane with the stop-line (traffic light) and the section of speed limit [11]. Investigation of traffic delays at controlled intersections were conducted over a long period, but no accurate results have been obtained yet, which are incorporated into the program of simulation of the motion of vehicles. Many existing programs and projects of Ukrainian and foreign authors serve as an instrument in the estimation of the traffic flow modes operation. Within their framework there is a research, modeling and analysis of the state of the urban road network $[12,13]$. 
Alternative traffic management schemes at the intersections can reduce traffic delays and improve road safety. Authors [14] developed forecasting models for accidents, which evaluate the impact of different left turn organizations at the intersection. The analysis showed that the arrangement of left-turn flows at the four-legged intersection with all permitted directions is not safe, because such roadway features as parking on the roadside and near the intersection, can increase the possibility of an accident, because of left turns can limit visibility and create safety issues.

Also, the improvement of transport networks requires the study of the patterns of the change of their basic traffic flows parameters after making any project decisions. That is why, to evaluate the functioning of complex intersections, it is necessary to pay attention to the reduction of the general environmental pollution in cities [15].

To solve the question of the urban transport systems design, quite a large amount of program products is developed. It is necessary to admit that a larger part of them provides the opportunity to simulate objects for both public and individual transport systems. PTV VISSIM is the multipurpose package for traffic flow simulation at the micro-level. It is widely used in Europe, the USA, and other countries. The package is designed for the analysis and optimization of urban and long-distance transport connections. Software program allows to simulate city intersections by any complexity and control type, analyzing transport systems capacity and testing different traffic management schemes.

In the PTV VISSIM software program, Wiedermann's model is implemented, which describes the driver's behavior. Such human psychophysiological state as reduction of attention and reaction time necessary for making the decisions are considered. PTV VISSIM provides an opportunity to collect statistics on any section of the transport network and form reports, create presentations and videos [16]. That is why, simulating the investigated road network section can reveal all existing drawbacks of traffic management schemes, receive the main characteristics of traffic flow in analytical form, and also help to make and implement project decisions at investigated controlled intersections.

\subsection{Analysis of existing traffic organization scheme at controlled intersection of Lypynskoho-Promyslova-Mykolaichuka Streets}

Investigated territory consists of residential, public buildings, and also transport infrastructure objects. On approaches to the intersection, the parking is forbidden. Intersection of LypynskohoPromyslova-Mykolaichuka Streets is located in Shevchenkivskyi district of Lviv city and it is schematically given in Fig. 1.

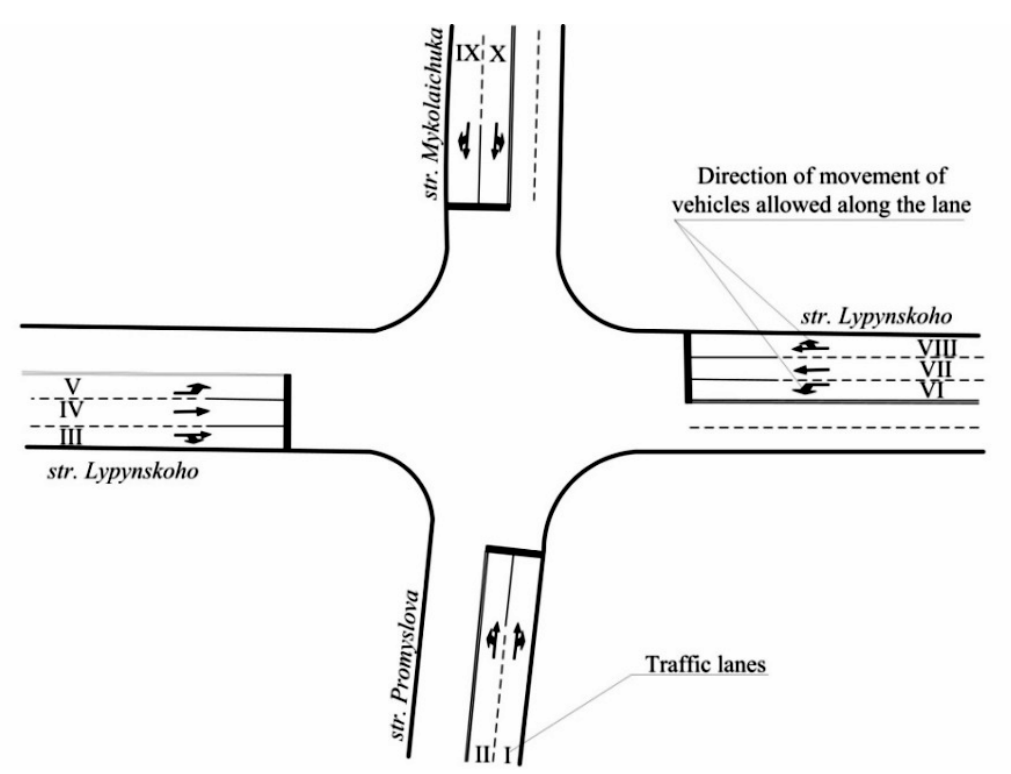

Fig. 1. Existing scheme of traffic flows movement at controlled intersection of Lypynskoho-Promyslova-Mykolaichuka Streets 
This intersection is characterized by a large number of public transport routes, including trams.

Intersection of Lypynskoho-Promyslova-Mykolaichuka Streets is controlled. Traffic phasing is in three phases. The existing traffic light cycle duration is $84 \mathrm{sec}$. In an existing scheme at the controlled intersection of Lypynskoho-Promyslova-Mykolaichuka Streets, at the approaches from Mykolaichuka and Promyslova Streets the traffic marking, which informs drivers about allowed movement directions on the lanes, is absent. It is due to the pavement on these entrences is made of cobblestone.

At the controlled intersection of Lypynskoho-Promyslova-Mykolaichuka Streets, left-turn flows move in the second phase. Even at insignificant intensity of these flows, continuous delays occur on these lanes. Partly, it is connected with the small duration of the permission signal in the control phase. Also, for the performance of the left turn maneuver at the intersection and the safe passage in the intersection zone, vehicles need more time as they delineate a bigger radius of movement. That is why, to reduce the traffic delays, to increase the safety at the intersection and allow the reduction of the delay duration and queue length on the approaches to the intersection, project decisions should be made. In the zone of controlled intersection on Lypynskoho St. is 3 by 3 lanes (the right lane is for straight and right-turn flows, the middle lane is for straight flows, and the left lane is for left-turn flows).

\subsection{Investigation of vehicle delays at the controlled intersection of Lypynskoho-Promyslova- Mykolaichuka Streets by the method of movement accounting on stationary posts}

There are different methods for measuring the time of intersection passage and delays on it. During the investigation, the passage through intersection by vehicles on one or several approaches to it, the time of passage from the point before the intersection to the point at or after the intersection is measured. To obtain the data about the travel duration, such methods are used [8]:

1. Passage of control vehicle between fixation points.

2. Registration in fixation points of vehicle numbers and the time of their passage.

3. Frame-by-frame videotape recording in determined time intervals from the convenient position, which allows to follow the movement of every vehicle.

4. The usage of the tape counter, which is actuated by pneumatic encoder or observer with the switch.

5. Registration by the observer the time in critical points which every vehicle, passing the intersection, traces.

Scaled scheme of the intersection with observation points location and rows of motion on approaches to the intersection, in which vehicle queues are formed, is given in Fig. 2.

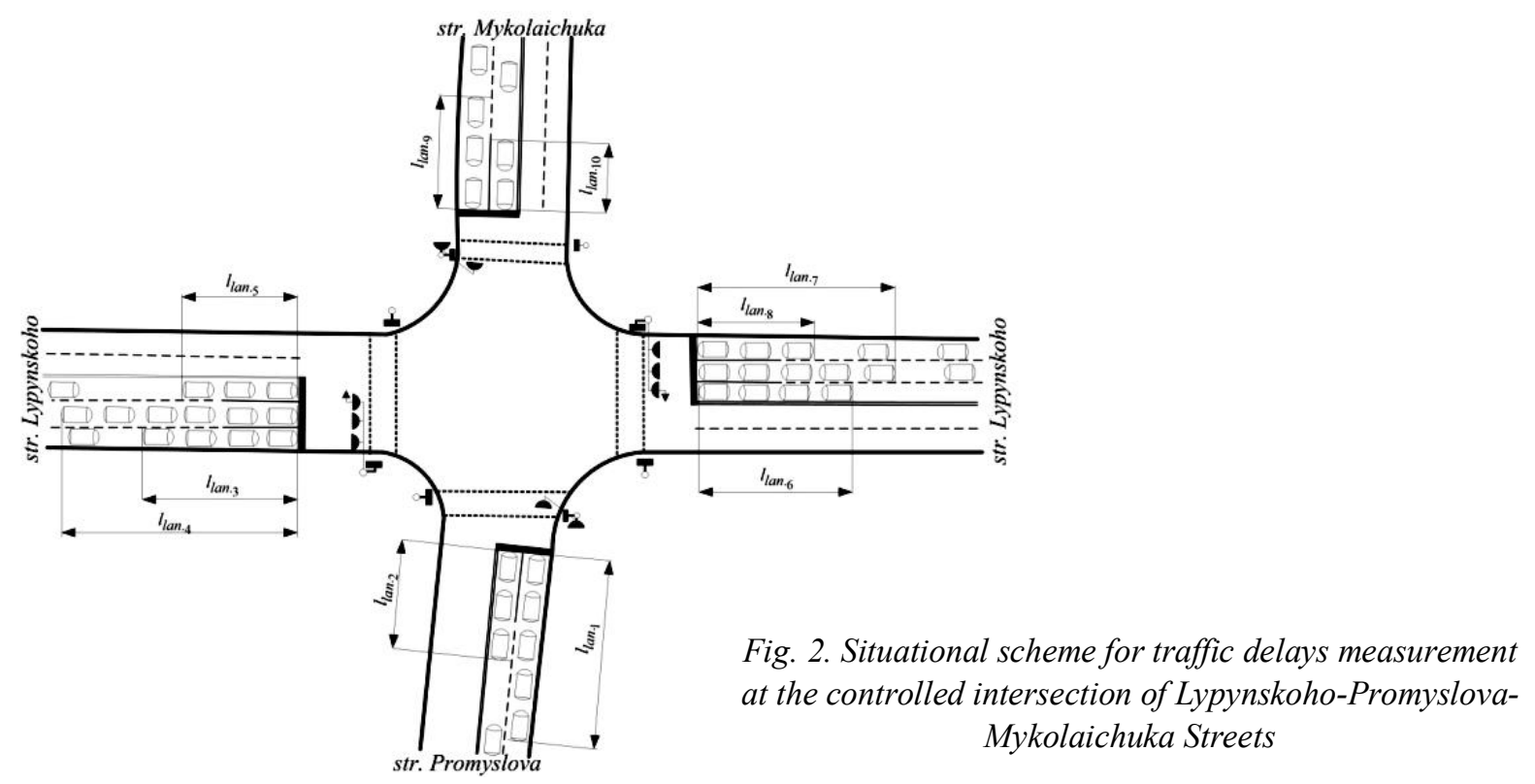


General summarized results of the average vehicle delay on all lanes according to the situational scheme of the intersection are given in Table 1.

Table 1

\section{Summarized results of traffic delay measurement at the controlled intersection of Lypynskoho-Promyslova-Mykolaichuka Streets}

\begin{tabular}{|c|c|c|c|}
\hline $\begin{array}{l}\text { Lane of movement } \\
\qquad\left(l_{\mathrm{sec}}\right)\end{array}$ & $\begin{array}{l}\text { General number of vehicles } \\
\text { that stopped on the approach } \\
\left(l_{s e c}\right) \text { in given time } \\
\text { moments, sec } \\
\left(\sum n_{s t_{n}}\right)\end{array}$ & $\begin{array}{l}\text { General number of } \\
\text { vehicles that passed the } \\
\text { intersection from the } \\
\text { approach } l_{\text {sec }} \\
\left(\sum n_{\text {pas }_{n}}\right)\end{array}$ & $\begin{array}{l}\text { Average vehicle delay } \\
\text { on the section } l_{s e c} \text {, sec } \\
\qquad\left(t_{\Delta_{n}}\right)\end{array}$ \\
\hline$l_{\sec 1}$ & 107 & 40 & 39 \\
\hline$l_{\sec 2}$ & 89 & 38 & 35 \\
\hline$l_{\sec 3}$ & 127 & 44 & 43 \\
\hline$l_{\sec 4}$ & 174 & 53 & 48 \\
\hline$l_{\sec 5}$ & 71 & 17 & 63 \\
\hline$l_{\sec 6}$ & 58 & 17 & 61 \\
\hline$l_{\sec 7}$ & 192 & 55 & 52 \\
\hline$l_{\sec 8}$ & 152 & 42 & 54 \\
\hline$l_{\sec 9}$ & 57 & 36 & 24 \\
\hline$l_{\sec 10}$ & 72 & 28 & 39 \\
\hline
\end{tabular}

The average vehicle delay at the intersection is $45 \mathrm{sec}$. The least delays are in the sections 2 and 9 (35 sec in Promyslova St. on the lane for left-turn and straight flows and $24 \mathrm{sec}$ in Mykolaichuka St. on the lane for straight and right-turn flows.

The largest delay is in section 5 and section 6 (left-turn flows on the main road) and is 63 and $61 \mathrm{sec}$ as the duration of green signal in this direction is insufficient $(8 \mathrm{sec})$.

So, the analysis of obtained results of traffic delays measurement points to the flows where there are the largest delays in movement. That is why during the development of project decisions about the increase of the effectiveness of complex intersections functioning it is necessary to examine general traffic delays and the reasons for their occurrence.

\subsection{Traffic organization in the absence of left-turn flows at the controlled intersection and the evaluation of its operation by the results of the simulation}

To increase the effectiveness of the operation of Lypynskoho-Promyslova-Mykolaichuka St. intersection, it is proposed to forbid left-turn traffic flows on the main road (Lypynskoho St.). It will help to optimize the main indicators of traffic flow, traffic light cycle, reduce queue length on the approaches to the intersection and time for intersection passage, liquidate dangerous maneuvers and increase traffic safety. Restriction of the left-turn flows at the complex intersection allows to implement two-phase traffic light control at the intersection. Forbidden left-turn maneuvers on the arterial Lypynskoho St. will be implemented at adjacent intersections as given in Fig. 3.

In the second phase, traffic flows No. 5 and No. 6 moved. Traffic flow No. 5 can perform left-turn maneuver only at the roundabout intersection of Lypynskoho-Khmelnytskoho St. which is located at a distance of $600 \mathrm{~m}$. Traffic flow No. 6 can perform its maneuver at the intersection of MykolaichukaPoltviana-Linkolna St. which is located at a distance of $170 \mathrm{~m}$.

Increase of the effectiveness of the functioning of Lypynskoho-Promyslova-Mykolaichuka St. intersection implies the liquidation of turning traffic flows in Lypynskoho St., for which separate control phase was earlier allocated. On the approach to the intersection, these flows are combined with straight flows, and the possibility for desired maneuver performance (turning) is restricted at the intersection. 
Implementation of this solution will allow to avoid the potential conflict situations at the intersection, and also to increas the traffic safety.

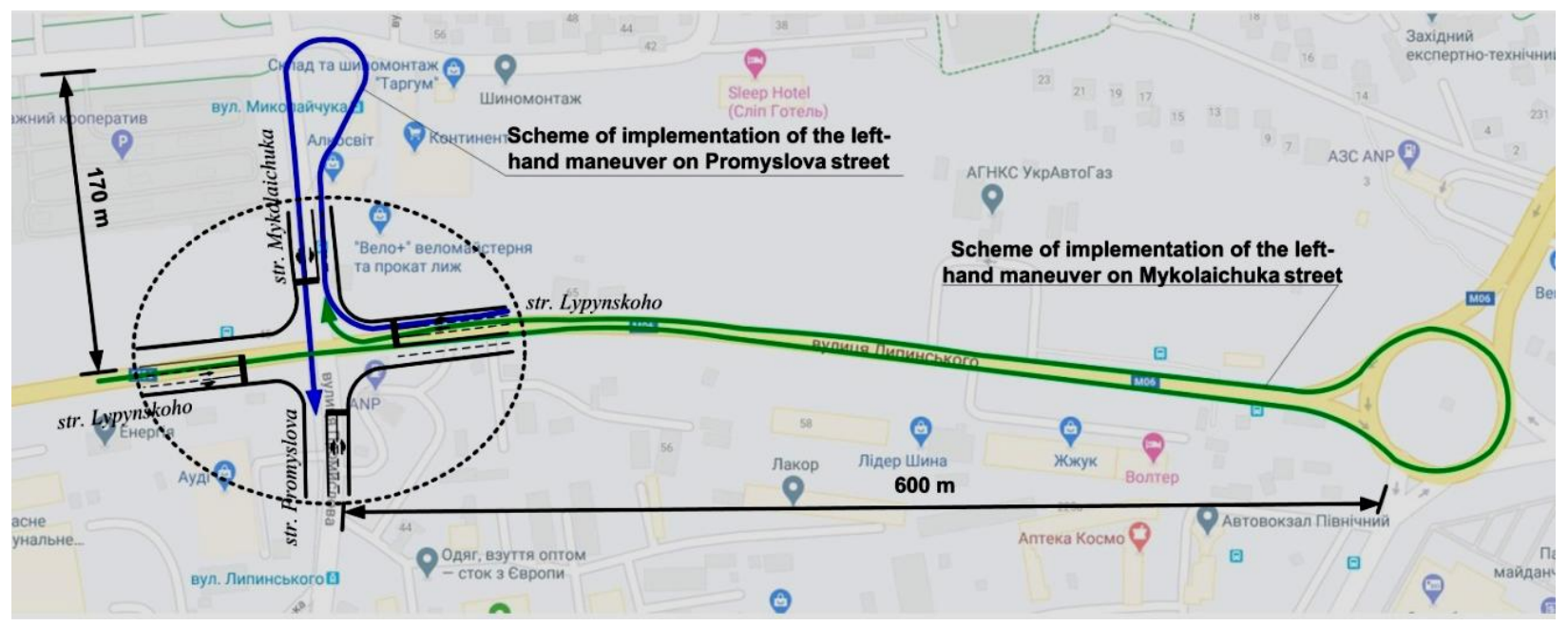

Fig. 3. Scheme of implementation of left-turn maneuvers in Lypynskoho St.

According to the main principles of traffic phasing, restriction of the left-turn maneuvers at the intersection allows to short the number of phases on the traffic light cycle from three to two, promoting the optimization of traffic light cycle duration. Traffic phasing at the controlled intersection of LypynskohoPromyslova-Mykolaichuka St. in the absence of intensive left-turn flows is given in Fig. 4.
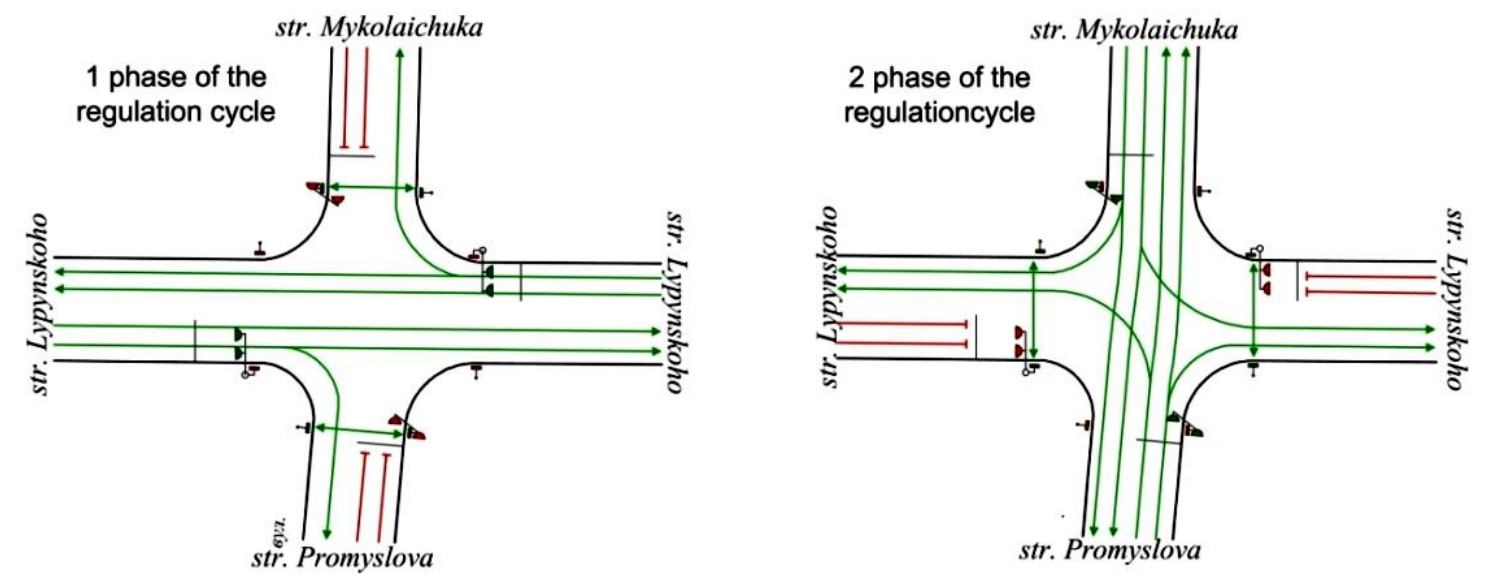

Fig. 4. Traffic flow phasing at the controlled intersection of Lypynskoho-Promyslova-Mykolaichuka Streets in the absence of intensive left-turn flows in Lypynskoho St.

After restriction of the left-turn maneuvers at the intersection and the number of phases contraction in the traffic light cycle, the calculation of saturation flows and phase coefficients for every phase was carried out. Improved traffic light cycle at the intersection of Lypynskoho-Promyslova-Mykolaichuka St. is 69 sec. Restriction of the left-turn maneuvers at this intersection allows to optimize the traffic light cycle duration.

In the first phase, traffic flows on the main road move. The duration of the control phase is $31 \mathrm{sec}$. Also, in the first phase pedestrians move along Promyslova and Mykolaichuka St. The duration of the second phase is $30 \mathrm{sec}$. The duration of the yellow signal is $4 \mathrm{sec}$.

During the calculation of the control phase, the left-turn intensity with flows on the minor road has not exceeded $120 \mathrm{pcu}$. That is why the part of the flow can perform the maneuver of the left turn during the second control phase. In this phase, traffic flow moves from the minor road and pedestrians cross the roadway. 
Traffic flow simulation based on the change of movement conditions at intersection of LypynskohoPromyslova-Mykolaichuka St. will be performed in PTV VISSIM software program. Performance of simulation modeling in PTV VISSIM software program provides the opportunity to investigate the regularities of the traffic flows change at the intersection. To create the model, it is necessary to build streets approaching the intersection, which are connected with each others by connecting segments according to allowed movement directions. Also, movement priorities are given in locations of the formation of conflict points between vehicles and pedestrians. The simulation model of LypynskohoPromyslova-Mykolaichuka St. intersection, created in PTV VISSIM software program, is given in Fig. 5.

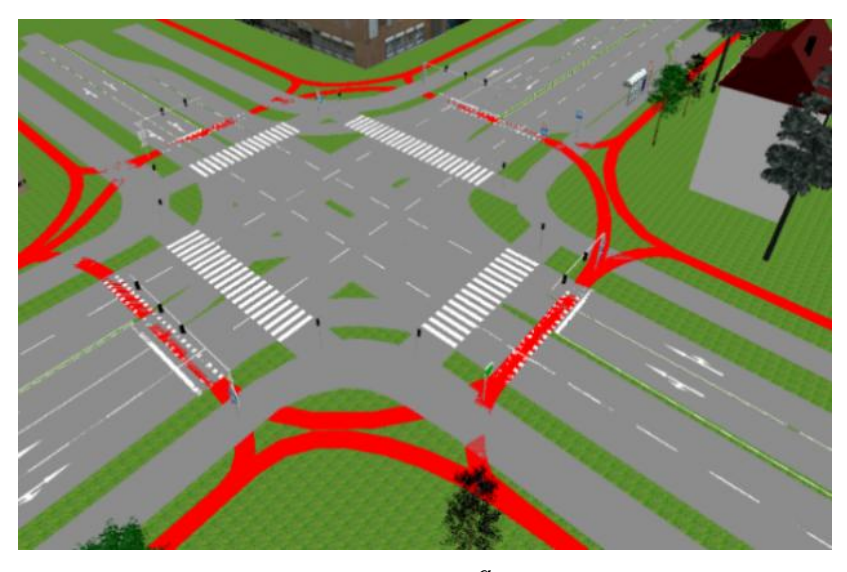

$a$

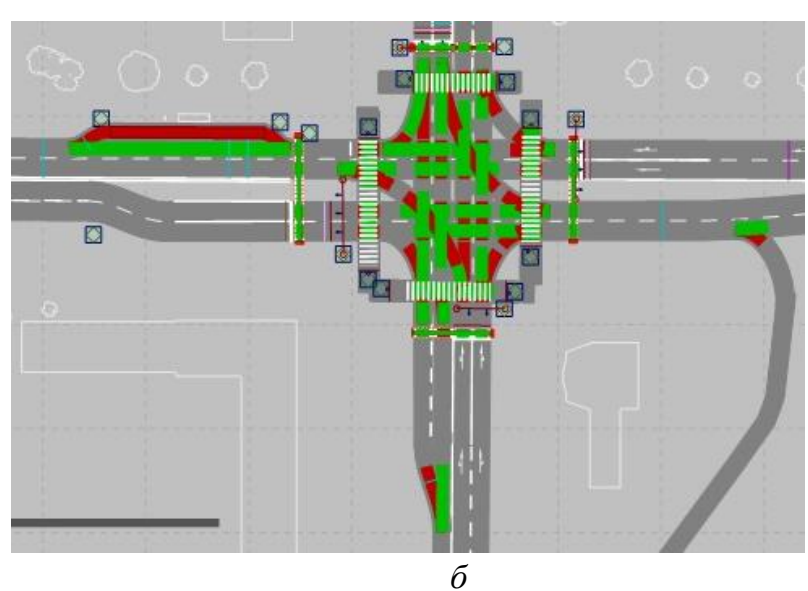

$\sigma$

Fig. 5. Simulation model of Lypynskoho-Promyslova-Mykolaichuka St. intersection created in PTV VISSIM software (a) with movement priorities (b)

Also, in accordance with the results of field research, entrance traffic flows are formed with appropriate composition, intensity, and speed of vehicle movement, and also their distribution by directions are formed in PTV VISSIM software program. Simulation of intersection operation is in the improved regime of traffic light control and without left-turn flows. As adjacent intersections, where the realization of left-turn maneuvers are taken, are not far from the controlled intersection, it provides the opportunity to examine the intensity of turn flows, and also the peculiarities of their behavior, for the minimization of the average delay and increase of traffic safety at all at the intersection.

The main factors that will be determined during the simulation of intersection operation are maximal vehicle queue length before stop-line, the average queue length and time in traffic jam. For this purpose, we set measurement points on every lane before the intersection. The duration of the simulation was $10 \mathrm{~min}$. Simulation results of these indicators relatively to the stop-line considering passenger car unit intensity and the duration of the restrictive signal are given in Table 2.

Table 2

\section{Simulation results on every lane at the intersection in PTV VISSIM software}

\begin{tabular}{|c|c|c|c|c|c|c|}
\hline \multirow[b]{2}{*}{$\begin{array}{c}\text { Measurement } \\
\text { point }\end{array}$} & \multicolumn{2}{|c|}{ Average queue length, $\mathrm{m}$} & \multicolumn{2}{|c|}{ Maximal queue length, $\mathrm{m}$} & \multicolumn{2}{|c|}{ Time in traffic jam, sec } \\
\hline & $\begin{array}{c}\text { At the } \\
\text { existing } \\
\text { scheme at the } \\
\text { intersection }\end{array}$ & $\begin{array}{l}\text { After restriction } \\
\text { of the left-turn } \\
\text { flows at the } \\
\text { intersection }\end{array}$ & $\begin{array}{l}\text { At the existing } \\
\text { scheme at the } \\
\text { intersection }\end{array}$ & $\begin{array}{l}\text { After restriction of } \\
\text { the left-turn flows } \\
\text { at the intersection }\end{array}$ & $\begin{array}{c}\text { At the } \\
\text { existing } \\
\text { scheme at the } \\
\text { intersection }\end{array}$ & $\begin{array}{l}\text { After restriction of } \\
\text { the left-turn flows } \\
\text { at the intersection }\end{array}$ \\
\hline 1 & 2 & 3 & 4 & 5 & 6 & 7 \\
\hline 1 & 66.9 & 39.74 & 103.3 & 94.55 & 38.3 & 19.59 \\
\hline 2 & 91.5 & 84.7 & 91.2 & 81.1 & 72.7 & 53.41 \\
\hline 3 & 24.4 & 31.7 & 109.8 & 67.36 & 48.3 & 43.72 \\
\hline
\end{tabular}


Table continuation 2

\begin{tabular}{|c|c|c|c|c|c|c|}
\hline 1 & 2 & 3 & 4 & 5 & 6 & 7 \\
\hline 4 & 35.4 & 11.61 & 68.8 & 74.27 & 76.1 & 72.51 \\
\hline 5 & 60.2 & 13.1 & 194.6 & 111.63 & 63.5 & 61.62 \\
\hline 6 & 55.5 & 47.4 & 75.31 & 118.87 & 72.2 & 40.04 \\
\hline 7 & 67.1 & 50.66 & 123.1 & 125.68 & 51.7 & 22.74 \\
\hline 8 & 44.1 & 54.46 & 92.6 & 83.55 & 57.3 & 65.16 \\
\hline
\end{tabular}

Simulation results of maximal queue length at the designed traffic organization scheme point to its reduction. But, there are such lanes as VIII and IX on which the increase of the maximum queue length is observed at the expense of redistribution of left-turn maneuvers by performance of right turn. On lane VIII, an increase of maximal queue length from 75.3 to $118.7 \mathrm{~m}$ can be explained by the fact of the vehicle queue growing due to conflict with pedestrians as in the first phase the movement of right-turn and pedestrian flows is combined.

On the basis of obtained simulation results of the controlled intersection operation of LypynskohoPromyslova-Mykolaichuka St., the average queue length at the intersection is defined in existing movement conditions and at restriction of the left-turn flows at the intersection. Graphical analysis of the investigation results of the impact of traffic organization scheme at the intersection on the average queue length is given in Fig. 6.

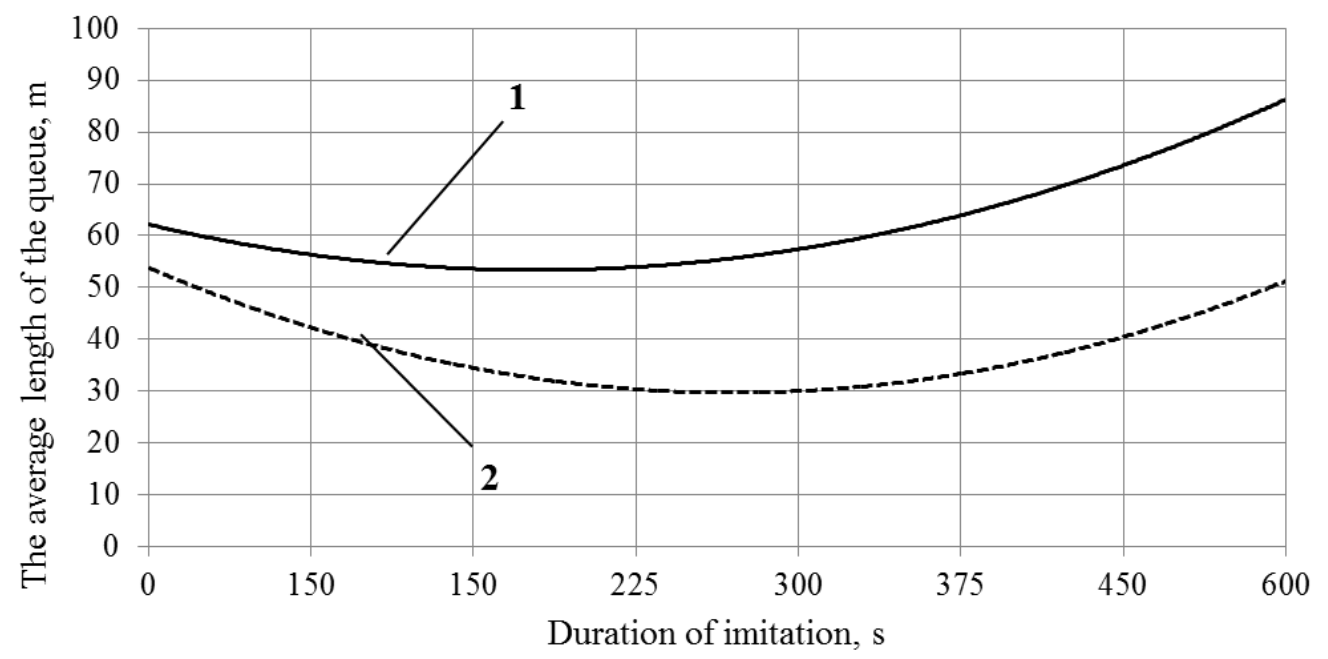

Fig. 6. Change of the average queue length at the controlled intersection of Lypynskoho-Promyslova-Mykolaichuka Str. in existing traffic organization scheme (1) and restriction of the left-turn flows at the intersection (2)

Having analyzed the graph of the change of the average queue length at the controlled intersection of Lypynskoho-Promyslova-Mykolaichuka St., it should be noted, that restriction of the left-turn flows at the intersection has a positive impact on the operation of the whole intersection. From the beginning of the simulation, the average queue length was not significantly different and was approximately $60 \mathrm{~m}$ in both variants of traffic organization. Further, the average queue length at the intersection tends to decrease, it happened because the phase for left-turn flows was not allocated, and vehicles that wanted to perform this maneuver, went straight and there was no deceleration in the traffic flow.

Further growth of the average queue length at the intersection can be explained by the fact that vehicles that wanted to turn left but, according to the movement scheme without left-turn flows, made a detour. Respectively, for a while (2-3 min), vehicles arrived at the intersection and the number of vehicles waiting for the permission signal before the stop-line increased causing the queue length growth Because of this, the average queue length at the intersection increases. Also, the increase of the average queue length is connected with the presence of trams in traffic flow in Promyslova and Mykolaichuka St., which 
slow down the whole traffic flow by their dynamic characteristics, especially if they are the first before the stop-line. It can be noted, that in general, queue length at the whole intersection without left-turn flows decreases by $35 \%$.

\section{CONCLUSIONS AND RESEARCH PERSPECTIVES}

Field research of traffic flow indicators at the controlled intersection of Lypynskoho-PromyslovaMykolaichuka St. is carried out. Every approach to this intersection has minimum two lanes in every direction. Traffic phasing at the intersection has three phases, and the duration of the traffic light cycle is $84 \mathrm{sec}$. At the intersection, straight flows prevail and a significant share of left-turn flows exist. By the composition at the intersection, the share of cars is $78 \%$, and the share of left-turn and right-turn flows is $18 \%$.

The measurement of traffic delays at the controlled intersection on every lane has been carried out and it has been determined that the average vehicle delay in general on all approaches to the intersection at the existing traffic organization is $45 \mathrm{sec}$. The least delays in movement are at the secondary Promyslova and Mykolaichuka St.

To simulate the movement at the controlled intersection, two models has been created which provide an opportunity to evaluate the effectiveness of its functioning at the existing conditions and considering the change of traffic organization scheme that is the restriction of the left-turn maneuvers at the intersection.

Based on the simulation in PTV VISSIM software, the maximal queue length before the stop-line, the average queue length and time in a traffic jam are determined, which, in comparison with the existing condition on the majority of lanes, have a pronounced trend to the reduction of summarized traffic delays.

It has been established that, the restriction of the left-turn maneuvers at the intersection of Lypynskoho-Promyslova-Mykolaichuka St., allows to optimize traffic light cycle and organize it in such way that the average traffic delay, in comparison to the existing condition, decreases by $35 \%$.

As the simulation results of the change of the average queue length before the stop-line for different planning and engineering solutions at the intersection show, the largest queue length is during the performance of turn maneuvers, especially the left-turn. Also, with the increase of traffic intensity in cities, the existing traffic light cycles do not cope with the passage of all vehicles before the stop-line. Further growth of the volume-capacity ratio will cause the congestion. That is why, to satisfy the need for vehicles and pedestrians movement, at the intersections with traffic lights it is necessary to examine traffic organization schemes and equip intersections from the point of minimization of queue length on the approaches to intersections.

In the future, to solve transport problems at the intersections, it is necessary to create simulation models that will reflect their operation. It will allow to forecast the change of traffic flow indicators at complex intersections more precisely, even at the change of the measures of organizational character on them. Also, it would be advisable to carry out an assessment of the change in vehicle and harmful emissions into the air at restriction of the the left-turn flows at the intersection. The development of quantitative criteria for the feasibility of decisions regarding the fact of restriction of the left-turn flows at the intersection should be the end result of research in this direction.

\section{References}

1. Boikiv M. V., Zytenko O. V. \& Dichtyr O. V. (2018) Analiz prychyn vynyknennia dorozhno-transportnykh podii $\mathrm{v}$ Ukraini [Analysis of the causes of traffic accidents in Ukraine].Vcheni zapysky Tavriiskoho natsionalnoho universytetu imeni V. I. Vernadskoho. Seriia: Tekhnichni nauky» [Scientific notes of the V. I. Vernadsky National University. Series: Technical Sciences]. Volume 29 (68), № 2, 290-294. (in Ukrainian).

2. Pauw, Ellen \& Daniels, Stijn \& Herck, Stijn \& Wets, Geert. (2015). Safety Effects of Protected Left-Turn Phasing at Signalized Intersections: An Empirical Analysis. Safety. 1. 94-102. doi: 10.3390/safety1010094. (in English).

3. Amiridis, Kiriakos \& Stamatiadis, Nick \& Kirk, Adam. (2017). Safety-Based Left-Turn Phasing Decisions for Signalized Intersections. Transportation Research Record: Journal of the Transportation Research Board, 2619, 13-19. doi: 10.3141/2619-02. (in English). 
4. Stamatiadis Nick, Hedges Adam \& Kirk Adam. (2015). A simulation-based approach in determining permitted left-turn capacities. Transportation Research Part C: Emerging Technologies. Volume 55. 486-495 doi: 10.1016/j.trc.2015.03.044. (in English).

5. Fornalchyk Ye. Yu. \& Hilevych V. V. (2010) Aktualizatsiia lokalnoho upravlinnia transportnymy potokamy mista [Updating local management of city traffic flows]. Visnyk Skhidnoukrainskoho natsionalnoho universytetu im. V. Dalia [Bulletin of the East Ukrainian V. Dalia National University]. Volume 6. 24-28. (in Ukrainian).

6. Wei, Fulu \& Wang, Zhenyu \& Lu, Jian. (2017). Exploring factors contributing to lane changes during left turns on quadruple left-turn lanes at signalized intersections. Advances in Mechanical Engineering. Volume 9. 1-9. doi:10.1177/1687814017700062. (in English).

7. Bhuiyan, Nasima. (2015). Left turn treatment and Safety study at signalized intersections. Technical Repor. Course Title: S Topics Engineering. doi: 10.13140/2.1.2826.2728. (in English).

8. Havrylov E. V., Dolia V. K., Lanovyi O. T. et al. (2005) Systemolohiia na transporti. Orhanizatsiia dorozhnoho rukhu : knyha 4 [Systemology in transport. Organization of traffic: Book 4. Kyiv: Znannya Ukrayiny. (in Ukrainian)

9. Hryhorov M. A. \& Dashchenko O. F. (2004) Problems of modeling and control of traffic flow in large cities. Odessa: Astroprynt. (in Ukrainian).

10. Kienast, Henning \& Schmitz, Marcus \& Rittger, Lena \& Neukum, Alexandra. (2018). Human machine interface (HMI) for Left Turn Assist (LTA). SAE Technical Papers. Volume 11(1). 16-29. doi: 10.4271/07-11-010002. (in English).

11. Fornalchyk Ye., Mohyla I. \& Hilevych V. (2013) The saturation flow volume as a function of the intersection passing speed . International Scientific Journal «Transport Problems». Volume 8. 43-52. (in English).

12. Wasson, Jay \& Abbas, Montasir \& Bullock, Darcy \& Rhodes et al. (1999). Reconciled Platoon Accommodations at Traffic Signals. Publication FHWA/IN/JTRP-99/01. Joint Transportation Research Program. doi: $10.5703 / 1288284313301$.

13. Teply S. (1997). Performance Measures in Canadian Capacity Guide for Signalized Intersections. Transportation Research Record. 1572. 148-159. doi: 10.3141/1572-18.

14. Turner, Shane \& Wood, Graham \& Tate, Fergus. (2019). The crash performance of seagull intersections and intersections with left turn slip lanes. Journal of the Australasian College of Road Safety. Volume 30. 37-47. doi: 10.33492/JACRS-D-18-00111.

15. Galkin A., Lobashov O., Capayova S., Hodakova D., Schlosser T. (2018) Perspective of decreasing of road traffic pollution in the cities. International Multidisciplinary Scientific GeoConference-SGEM, 4.2 (18), 547-554. doi:10.5593/sgem2018/4.2/S19.071. (inEnglish).

16. Kratkoe rukovodstvo po vypolnenyyu proektov v PTV Vissim 6 [Quick Guide to the implementation of projects in the PTV Vissim 6]. Retrieved from https://bespalovdotme.files.wordpress.com/2017/03/quickstart_vissim_6-0.pdf. (in Russian).

Received 03.03.2020; Accepted in revised form 27.03.2020. 